\title{
A SPATIAL Equilibrium ANALYSis of REgional Structural Change IN THE U.S. DAIRY INDUSTRY
}

\author{
Fari Yavuz, Gary Schnitkey, Carl Zulauf, and Mario Miranda*
}

September 1995

\author{
Agricultural Administration Building \\ Department of Agricultural Economics \\ Ohio State University \\ 2120 Fyffe Road \\ Columbus, Ohio 43210
}

* The authors are Assistant Professor, Ataturk University, and Associate Professors, Ohio State University. respectively. 


\section{A Spatial Equilibrium ANalysis of Regional Structural Change IN the U.S. DaiRy INDUStRy \\ Executive Summary}

Regional discord has increased in the U.S. dairy industry during recent years. An oftencited reason is regional shifts in milk production. Studies of the regional distribution of milk production have examined the impact of supply, demand, or policy variables, but no study has compared the relative importance of these variables in the same analysis. This study conducts such a comparative analysis, thereby addressing the question of which variable has the largest impact on regional shifts.

A static equilibrium model of spatially separated markets is constructed to model the movement of milk between regions. This model closely replicates the observed regional production shares for 1970,1980 , and 1991. These years span the period of greatest regional shifts in the U.S. dairy industry.

Given the model's close replication of the observed regional shifts over the 1970-1991 period, impact of a supply, demand, or policy variable on these shifts can be evaluated by substituting the 1970 values of a selected variable into the model for 1991 . The model is then resolved. Impact of changes in the selected variable between 1970 and 1991 is quantified by comparing the regional distribution of milk production from the resolved 1991 model with the distribution from the original model for 1991. This approach in essence uses the spatial equilibrium model as a historical analytical tool.

Supply variables had by far the dominant impact on regional changes in the U.S. dairy industry. Shift in per capita consumption of dairy products to cheese and a 30 percent decline 
in the milk support price had some impact. Regional shifts in population and per capita income, as well as the 1986 changes in Class I fluid milk price differentials, had almost no impact.

These results underscore the importance of supply variables in understanding regional shifts in milk production. They do not support complaints that changes in the fluid milk differentials affected the regional distribution of milk production. Furthermore, future declines in the support price is expected to negatively impact milk production in the West and especially the Corn Belt, while positively impacting production in the Lake States and Southeast. 


\section{A Spatial Equilibrium analysis of Regional Structural Change IN THE U.S. DaIRY INDUSTRY}

Regional discord has increased in the U.S. dairy industry during recent years. An oftencited reason is regional shifts in milk production (for example, Blayney and Southard). Studies of the regional distribution of U.S. milk production have examined the impact of federal milk marketing orders (McDowell and Schiek), federal price support policy (Hallberg, Hahn, Stammer, Elterich, and Fife; and McDowell), prices and associated elasticities of raw milk, milk products, and production inputs (Ruane and Hallberg; Batista; Chavas, Kraus, and Jesse; and Weersink and Howard), new technologies (Weersink and Tauer), and demand variables (Ruane and Hallberg). However, no study has compared the relative impacts of supply, demand, and policy variables in the same analysis, thereby addressing the question of which one of these variables has the largest impact on regional production shifts.

This study conducts such a comparative analysis. Results of the analysis should be of interest to dairy producers and milk cooperatives in all regions of the U.S., as well as to U.S. policy makers. The analysis is particularly timely given the current debate over dairy policy and its impact on the regional distribution of milk production.

\section{Approach}

A static equilibrium model of spatially separated markets is constructed to model the movement of milk between regions. The constructed model closely replicates the observed regional milk production shares for 1970, 1980, and 1991. These years span the period of historically large regional shifts in the U.S. dairy industry. They also span a wide range of 
market environments. Commodity prices, including milk, rose significantly during the 1970s, but declined during the 1980 s. The milk price support program provided significant downside protection from 1970 through the mid-1980s, but since 1985 its impact on prices has been less.

Given the model's close replication of the regional shifts in milk production over the 1970-1991 period, impact of a supply, demand, or policy variable on the regional distribution of milk production over this period can be evaluated by substituting the 1970 values of the selected variable into the model for 1991. The model is then resolved. Impact of changes in the variable between 1970 and 1991 can be quantified by comparing the regional distribution of milk production for the resolved 1991 model with the regional distribution generated by the original model for 1991. This approach in essence uses spatial equilibrium analysis as a historical analytical tool.

\section{Spatial Equilibrium Model}

Spatial equilibrium models first were formulated in a mathematical framework during the 1950 s by Samuelson. Solutions to these models can be obtained by maximizing consumer and producer surplus given that market behavior is competitive. The specific specification used in this study is Takayama and Judge's quadratic model for the case in which supply and demand functions are linear.

The model is composed of 10 regions among which raw milk and dairy products are shipped. The regions are the U.S. Department of Agriculture's production regions, which group states by similar production and geographical characteristics. They are: Northeast, Lake States, 
Corn Belt, Northern Plains, Appalachia, Southeast, Delta States, Southern Plains, Mountain, and Pacific. These regions are denoted by the subscript $\mathrm{i}$, where $\mathrm{i}=1, \ldots, 10$.

The model contains two stages. One is a production stage where farmers supply raw milk to processors who use raw milk for producing dairy products. The second stage is a processing stage where processors supply dairy products to retailers who sell the products to consumers. Dairy products are fluid milk, butter, cheese, nonfat dry milk, and other dairy products. Dairy products are denoted by the subscript $\mathrm{j}$, where $1=$ fluid milk, $2=$ butter, 3 $=$ cheese, $4=$ nonfat dry milk, and $5=$ other dairy products.

Each region has a production point, a processing point, and a retail point. For each region there are six supply functions: one for raw milk supplied by dairy farmers [i.e., $\alpha_{i}^{\text {Rs }}+$ $1 / 2 \beta_{i}^{R s} q_{i}^{R s}$, where $\alpha$ and $\beta$ are parameters of the $i^{\text {th }}$ region's supply function and $\mathrm{q}_{i}^{\mathrm{Rs}}$ is raw milk supplied by dairy farmers in the $\mathrm{i}^{\text {th }}$ region]; and one supply function for each of the five dairy products [i.e., $\alpha_{i}^{j s}+1 / 2 \beta_{i}^{j s} q_{i}^{\text {js }}$, where $q_{i}^{j s}$ is raw milk supplied by processors for the $j^{\text {th }}$ dairy product in the $\mathrm{i}^{\text {th }}$ region]. Each region also has seven demand functions: one for raw milk used to make fluid products [i.e., $\alpha_{i}^{\mathrm{Fd}}-1 / 2 \beta_{\mathrm{i}}^{\mathrm{Fd}} \mathrm{q}_{i}^{\mathrm{Fd}}$, where $\alpha$ and $\beta$ are parameters of the $i^{\text {th }}$ region's demand function and $\mathrm{q}_{\mathrm{i}}^{\mathrm{Fd}}$ is raw milk demanded for fluid manufacture in the $\mathrm{i}^{\text {th }}$ region]; one for raw milk used to make manufactured products [i.e., $\alpha_{i}^{M d}-1 / 2 \beta_{i}^{M d} q_{i}^{M d}$, where $q_{i}^{M d}$ is raw milk demanded for manufactured dairy products in the $\mathrm{i}^{\text {th }}$ region]; and one for the final demand of each of the five dairy products [i.e., $\alpha_{i}^{\text {jd }}+1 / 2 \beta_{i}^{j d} q_{i}^{\text {jd }}$, where $q_{i}^{\text {jd }}$ is the final demand for the $j^{\text {th }}$ dairy product in the $\mathrm{i}^{\text {th }}$ region]. Two demand functions are needed for raw milk in order to incorporate the blend pricing scheme implemented through federal milk marketing orders. 
Takayama and Judge's objective function maximizes the area between the excess demand and excess supply curves minus transportation costs. In context of this study, this function can be stated as follows:

\section{Maximize:}

$$
\begin{aligned}
& \sum_{i=1}^{10}\left[\alpha_{i}^{F d} q_{i}^{F d}-1 / 2 \beta_{i}^{F d}\left(q_{i}^{F d}\right)^{2}\right] \\
+ & \sum_{i=1}^{10}\left[\alpha_{i}^{M d} q_{i}^{M d}-1 / 2 \beta_{i}^{M d}\left(q_{i}^{M d}\right)^{2}\right] \\
- & \sum_{i=1}^{10}\left[\alpha_{i}^{R s} q_{i}^{R s}+1 / 2 \beta_{i}^{R s}\left(q_{i}^{R s}\right)^{2}\right] \\
+ & \sum_{i=1}^{10} \sum_{j=1}^{5}\left[\alpha_{i}^{j d} q_{i}^{j d}-1 / 2 \beta_{i}^{j d}\left(q_{i}^{j d}\right)^{2}\right] \\
- & \sum_{i=1}^{10} \sum_{j=1}^{5}\left[\alpha_{i}^{j s} q_{i}^{j s}+1 / 2 \beta_{i}^{j s}\left(q_{i}^{j s}\right)^{2}\right] \\
& -\sum_{i=1}^{10} \sum_{i=1}^{10} t_{i j}^{F} X_{i l}-\sum_{i=1}^{10} \sum_{i=1}^{10} t_{i l}^{M} X_{i l} \\
& -\sum_{i=1}^{10} \sum_{i=1}^{10} \sum_{N=1}^{5} t_{i l}^{N} X_{i l}^{N}
\end{aligned}
$$

where: $\quad q_{i}^{F d}$ : quantity of raw milk demanded for fluid milk in region $i$

$\mathrm{q}_{\mathrm{i}}^{\mathrm{Md}}$ : quantity of raw milk demanded for manufacturing in region $\mathrm{i}$

$q_{i}^{\text {Rs: }} \quad$ quantity of raw milk supplied in region $i$

$q_{i}^{\mathrm{j} d}$ : $\quad$ quantity of dairy products demanded in region $i$

$\mathrm{q}_{\mathrm{i}}^{\mathrm{j} s}$ : $\quad$ quantity of dairy products supplied in region $\mathrm{i}$

$\mathrm{XF}_{\mathrm{u}}$ : raw milk for fluid use shipped from region $\mathrm{i}$ to 1

$\mathrm{XM}_{\mathrm{i}}$ : raw milk for manufacturing use shipped from region $\mathrm{i}$ to 1

$\mathrm{X}_{\mathrm{i} 1}^{\mathrm{j}}$ : $\quad$ amount of diary products shipped from region $\mathrm{i}$ to 1

$\mathrm{t}_{\mathrm{i} 1 \mathrm{~F}}^{\mathrm{F}}$ : transportation cost of fluid milk from region $\mathrm{i}$ to 1

$\mathrm{t}_{\mathrm{i} 1}^{\mathrm{M}}$ : $\quad$ transportation cost of manufacturing milk from region $\mathrm{i}$ to $\mathrm{I}$

$\mathrm{t}_{\mathrm{i}}^{\mathrm{j}}$ : $\quad$ transportation cost of dairy products from region $\mathrm{i}$ to 1 
The objective function is quadratic in q. It is subject to four equilibrium constraints. First, raw milk and/or dairy products are shipped between regions only if the price difference is equal to or greater than the transportation cost between the regions. Second, the quantity of raw milk supplied and quantity of dairy products supplied (demanded) by a region equals the quantity of raw milk and dairy products produced within the region plus net shipments into and out of the region. Third, the quantity of a dairy product processed from raw milk is a constant proportion per unit of raw milk. Fourth, the price of raw milk plus the cost per hundredweight of processing raw milk equals the weighted average price of the dairy products produced from the raw milk.

The following restrictions also are imposed to capture the key elements of the federal milk marketing order and milk price support policies:

Blend Price:

$$
\mathrm{P}_{i}^{R s}=\frac{\mathrm{q}_{i}^{\text {Fd }} \mathrm{p}_{i}^{\text {Fd }}+\mathrm{q}_{i}^{M d} \mathrm{p}_{i}^{M d}}{q_{i}^{F d}+q_{i}^{M d}}
$$

Class I Fluid Milk Differentials

Price Support Policy

$$
\mathrm{p}_{\mathrm{i}}^{\mathrm{Fd}}-\mathrm{p}_{(\mathrm{M}-\mathrm{W})} \geq \mathrm{K}_{\mathrm{i}}
$$

where: $\quad \mathrm{p}_{(\mathrm{M}-\mathrm{w})}$ : Minnesota-Wisconsin fluid milk price level

$\mathrm{K}_{\mathrm{i}}$ : Class I fluid milk differential

$S P^{N}$ : $\quad$ support price level for product $\mathrm{j}$ 
Equation 2 calculates the raw milk price as a weighted average of fluid and manufacturing milk prices. This blend price is paid to producers of Grade A milk. Equation 3 requires that the difference between a region's fluid milk price and the raw milk price in Minnesota-Wisconsin must exceed or equal the Class I price differential assigned to that region's marketing order.

Equation 4 operationalizes the price support policy by modeling the government as a demand agent who ensures that the market price remains at or above the support price. The government accomplishes this objective by buying sufficient quantities of American cheese, butter, and nonfat dry milk.

To simplify the analysis, each region is assigned a representative marketing order $^{1}$. This marketing order's Class I price differential is assumed to apply to the entire region. In addition, California has its own pricing system which is not associated with the federal price support and milk marketing order systems. However, the Pacific region is composed not only of California, but also Oregon and Washington. For the sake of simplicity, the Class I differential for the Oregon-Washington milk marketing order is applied to California. This decision implies that, in this model, California's price may be affected by the national support price.

\section{Equation Specification and Data}

The slope coefficient of price in the supply and demand equations is computed from the elasticity of supply (demand) for a region as follows: 


$$
\beta=\epsilon \frac{q_{1}}{P}
$$

where $\beta$ : slope coefficient of the supply (demand) equation

$\epsilon$ : price elasticity of supply (demand)

q: quantity (cwt) of supply (demand) in the base year

p: supply (demand) price in the base year $(\$ /$ cwt)

Given the slope coefficient, the intercept term is computed as follows:

$$
\alpha=q-\beta P
$$

where $\alpha$ : intercept of the supply (demand) function.

The supply and demand functions are constructed using elasticities estimated by recent studies rather than duplicating their work. Because this study focuses on regional change in U.S. milk production over a 21 year period, long run supply elasticities are used to compute the intercept and slope coefficients for the regional supply functions. Long run supply elasticities for raw milk were estimated recently by Batista (1985), Weersink and Howard (1990), and Chavas et al. (1990). The elasticities from Weersink and Howard are used because they were estimated for the same regions defined in this study.

The price elasticities of supply for the various dairy products are from Sullivan, Wainio, and Roningen (1989)2 ${ }^{2}$. Own-price elasticity of demand for fluid milk is from Gould, Cox, and Perali (1990), while the own-price elasticities of demand for butter, cheese, and nonfat dry milk 
are from Sullivan et al. (1989). For other dairy products, the own-price elasticity of demand is from Huang (1985). All of these elasticities are available only for the nation. Thus, the same elasticity is used for all regions.

The transportation cost functions are derived from Moede. Moede's functions also were used by Hallberg et al. and Baker. Costs included in these functions are equipment, administrative salaries, labor, fuel, tires and tubes, lubrication, repairs and miscellaneous costs. The specific transportation cost functions are:

$$
\begin{aligned}
& \text { Raw manufacturing milk: } \quad t_{11}^{\mathrm{M}}=0.2152+0.0063 \mathrm{M}_{11}^{\mathrm{M}} \\
& \text { Raw fluid milk: } \quad \mathrm{t}_{11}^{\mathrm{F}}=0.4702+0.0046 \mathrm{M}_{11}^{\mathrm{F}} \\
& \begin{array}{l}
\text { Fluid milk: } \quad \mathrm{t}_{11}^{\mathrm{F}}=0.4812+0.0047 \mathrm{M}_{11}^{\mathrm{F}}
\end{array} \\
& \text { Butter: } \quad t_{11}^{\mathrm{B}}=0.00323 \mathrm{M}_{11}^{\mathrm{B}} \\
& \text { Cheese: } \quad t_{11}^{c}=0.00323 M_{11}^{c} \\
& \text { Dry milk: } \quad t_{11}^{D}=0.00323 \mathrm{M}_{11}^{\mathrm{D}} \\
& \text { Other Products: } \quad \mathrm{t}_{11}^{\mathrm{O}}=0.00645 \mathrm{M}_{11}^{\mathrm{O}}
\end{aligned}
$$

Because these equations were estimated for 1972 , they are adjusted to $1970,1980,1991$ price levels by using the U.S. Department of Commerce's Producer Price Index.

Spatial equilibrium models are based on point trading. Thus, a single trade point is designated for each region. These trade points are the geographic center of each region (George). Distances between the trade points are from Rand McNally's commercial atlas. Shipment of raw milk from one region to another is assumed to occur only in bordering regions at an average distance of 150 miles (Moede). Data for prices, quantities, and policy variables 
are collected from U.S. Department of Agriculture periodicals: Agricultural Prices, Dairy Situation and Outlook Report, Federal Milk Order Market Statistics, Milk Production, and Milk Production, Disposition, and Income.

\section{Model Verification}

The spatial equilibrium model is solved using the quadratic programming procedure in the General Algebraic Modeling System (Brooke, Kendrick, and Meeraus). Regional shares of milk production generated for 1970,1980 , and 1991, as well as the actual shares reported by the U.S. Department of Agriculture, are presented in Table 1. Ratio of the model-derived share to the actual share varies from 95 percent (Delta States, 1991) to 107 percent (Pacific, 1980). Furthermore, the changes in production share derived from the model are in the same direction as the actual changes in production share for all regions and time periods, except for the Lake States over the 1970-1980 period. The absolute difference between model-derived and actual share changes varies from 0 to 0.8 percentage points for $1970-1980,0$ to 0.6 percentage points for $1980-1991$, and 0 to 0.7 percentage points for $1970-1991$. In total, 23 of the 30 observations have a difference which is less than one-third of a percentage point.

Sensitivity analyses are conducted using the long run raw milk supply elasticities from Chavas et al. and Batista ${ }^{3}$. Ratio of a region's share of milk production estimated using these alternative supply elasticities to the share estimated using the initial model calibration ranges from 89 to 107 percent. The results are available from the authors. 
Taken together these results suggest that this simple, stylized model captures the major regional shifts in U.S. milk production over the 1970-1991 period: from the central, northern and eastern areas of the U.S. to the south and west, notably the Pacific and Mountain regions. The results also are robust to alternative specifications of the elasticities of supply of raw milk. However, like any model, it does not capture all real-world effects. Thus, the results need to be interpreted with caution and within the context of the model.

\section{Implementation of Comparative Analysis}

Given that the model is able to replicate with acceptable accuracy the regional distribution of U.S. milk production over the 1970-1991 period, the impact of key variables on the regional distribution over the 1970-1991 period can be evaluated by imposing the observed values of the variable for 1970 into the model for 1991. Comparing the resulting distribution of milk production with that generated by the original model for 1991 provides a measure of the impact of the variable on regional production shares over the 1970-1991 period.

Supply factors, such as milk per cow and cows per farm, are generally recognized as key factors influencing the regional distribution of U.S. milk production. However, it is not possible to disaggregated supply into its component factors within the context of the chosen methodology. The reason is that milk per cow and cows per farm are strongly, inversely correlated. Consequently, the supply factors are treated as one variable.

Impact of the changes in supply factors between 1970 and 1991 is analyzed by first multiplying the share of U.S. milk production in each region in 1970 by total U.S. milk 
production in 1991 . This calculation distributes 1991 milk production according to the regional distribution which existed in 1970. This modified 1991 distribution of milk production is inputed into the model by recalibrating the intercept of the regions' supply equations. The model for 1991 then is resolved.

In contrast to supply, a disaggregated approach is used for demand because data on consumption of dairy products by retail consumers are not available for either the 10 regions or the states which compose them. Consumption of a dairy product by a region is estimated by multiplying the population in the region by national per capita consumption of the dairy product. Given this calculation, the impact of changes in the regional distribution of population and national per capita consumption of dairy products between 1970 and 1991 are evaluated. In addition, the conceptually important variable of per capita income is evaluated.

Over the 1970-1991 period, U.S. population shifted south and west. Population increased at an annual rate that exceeded 2.4 percent in the Southeast, Southern Plains, Mountain, and Pacific regions, but less than 1.3 percent per year in all other regions (U.S. Department of Commerce). Impact of this shift is analyzed by first calculating the share of U.S. population in each region in 1970. These ratios are then multiplied by the U.S. population in 1991 to distribute the 1991 population according to the regional distribution which existed in 1970 . This modified distribution of U.S. population is inputed into the model by recalibrating the intercept of the demand equation.

U.S. per capita consumption of cheese increased from 11.4 to 25.0 pounds between 1970 and 1991, but decreased for fluid milk, butter, nonfat dried milk, and other dairy products 
(Putnam and Allshouse). In total, consumption of all dairy products expressed in milk equivalent remained constant: 564 pounds in 1970 and 565 pounds in 1991 . Thus, the major change was a shift toward the consumption of cheese and away from all other dairy products. Impact of this shift is analyzed by recalibrating the intercepts of the regional demand equations to reflect the 1970 per capita consumption levels of dairy products.

Per capita income growth from 1970 to 1991 was relatively similar across the different regions, ranging from 1.8 percent per year in the Corn Belt to 2.7 percent per year in Appalachia and the Southeast. Given the relatively small difference among the regions and the inelastic income demand for dairy products, it is expected that per capita income will have little impact on the regional distribution of U.S. milk production.

Analysis of per capita income is conducted by first expressing a region's per capita income in 1970 as a ratio of U.S. average per capita income in 1970. These percents were then multiplied by average U.S. per capita income in 1991 to derive a modified regional distribution of per capita income. The percentage difference between a region's modified per capita income and its 1991 value was multiplied by the income elasticity of demand for a dairy product. This value then was used to adjust the intercept of the regional demand function for the dairy product. The income elasticities for the dairy products are taken from the most current study available (Heien and Wessells, 1988).

Analysis of the milk price support program is implemented by inputing the 1970 support prices, adjusted to 1991 levels using the Producer Price Index, into the price support equation of the original 1991 model. Support prices for butter, cheese, and nonfat dry milk in 1991 were 
99, 110, and 85 cents per pound, respectively. In comparison, 1970 support prices, adjusted to 1991 levels, were 196,147 , and 77 cents per pound, respectively. Over the analysis period the real support price decreased for butter and cheese, but increased for nonfat dry milk. In aggregate, the support price for manufacturing grade milk was $\$ 13.18$ per hundredweight in 1970 expressed in terms of 1991 dollars and $\$ 10.10$ per hundredweight in 1991 . Thus, over the analysis period the real support price for raw milk declined approximately 30 percent.

The Federal Milk Marketing Order Program was enacted in 1937 to assure consumers of sufficient supplies of fluid milk during all seasons of the year. Prior to May 1986, minimum Class I fluid milk price differentials for a milk order increased by about 15 cents per hundredweight for every 100 miles from the base point of Eau Claire, Wisconsin (Fallert, Blayney, and Miller). However, to reflect the ability of milk cooperatives to bargain for higher fluid milk prices, the Food Security Act of 1985 raised the minimum Class I differentials in 35 of the 44 marketing orders operating in May 1986. The price differentials increased the most for the Southeast, Delta, and Southern Plains.

Impact of this change is analyzed by inputing the pre-1986 Class I price differentials into the original model for 1991 . The differential are not adjusted for inflation because they were adjusted only once over the period analyzed and because the rationale for the adjustment was not related to inflation. 


\section{Results}

Between 1970 and 1991, differential changes in supply factors among the different regions caused U.S. milk production to shift to the Southern Plains and the west (Table 2). The largest increase in share of production associated with supply factors was four percentage points by the Pacific region, while the largest losses were 1.72 and 1.35 percentage points in the Corn Belt and Northern Plains, respectively. Differential changes in supply factors among the regions had a negative impact upon the share of production in both traditional milk production regions, the Northeast and Lake States.

Among the three demand factors, the shift to consumption of cheese had the greatest impact upon the regional distribution of milk production. This shift caused the share of production to increase by about one-third of a percentage point in the Northeast, Lake States and Corn Belt. Each of these regions are large producers of cheese, and thus would be expected to gain from a shift in consumption toward cheese. In contrast, the Pacific region's share of production declined by three-quarters of a percentage point.

Differential changes across regions in population and per capita income caused extremely small changes in production shares. In all cases, the absolute change in a region's production share was less than 0.04 percentage points. While the small impact of per capita income was expected, the small impact of population was surprising. Examination of the results generated by the analysis revealed that the increased consumption in southern and western regions caused by population shifts was largely met through increased shipments of fluid milk and dairy products from eastern and northern regions. 
The 30 percent decline in real support prices for milk between 1970 and 1991 were associated with a 0.55 percentage decline in the Corn Belt's share of U.S. milk production. The Mountain and Pacific region's share also were smaller, by 0.16 and 0.26 percentage points, respectively. In contrast, production share of the Lake States and Southeast increased by 0.30 and 0.21 percentage points, respectively.

Impact of changes in the Class I fluid milk price differentials authorized by the Food Security Act of 1985 was extremely small, with the largest absolute change in a region's production share being 0.03 percentage points for the Lake States and Appalachia. Schiek also found that the change in Class I price differentials produced only a small impact upon the regional distribution of milk production. A potential explanation for the limited impact of Class I differentials is that they apply only to the approximately 45 percent of milk processed for fluid consumption.

On a comparative basis, supply factors had the largest impact for all regions except the Southeast. for which the support price had the largest impact. The only other region where supply factors did not dominate was the Lake States, where the impact of supply factors was more than offset by the shift to cheese consumption and the relative changes in milk support prices.

To examine if the relative importance of the variables changed over the period analyzed. sub-period analyses were conducted for 1970-1980 and 1980-1991. While the level of the impact of some variables differed somewhat between the two periods for some regions, the 
relative relationship among the variables remained the same. To conserve space, these results are not presented; but are available from the authors.

\section{Summary and Conclusions}

Regional discord has increased in the U.S. dairy industry during recent years. An oftencited reason is regional shifts in milk production. Previous studies have examined the impact of supply, demand, or policy variables on the regional distribution of U.S. milk production. However, no study has compared the relative importance of the three types of variables in the same analysis, thereby addressing the question of which of these variables is most important.

A static equilibrium model of spatially separated markets is constructed to model the movement of milk between regions. The constructed model closely replicates the observed regional milk production shares for 1970, 1980, and 1991. These years span the period of greatest regional shifts in the U.S. dairy industry.

Among the variables analyzed, differential changes in supply factors among the regions had the largest impact upon the regional distribution of U.S. milk production over the 1970-1991 analysis period. The next largest impacts were generated by the shift in per capita consumption toward cheese and away from other dairy product and by changes in the real support price for American cheese, butter, and nonfat dry milk. To illustrate the dominant impact of supply factors, the average absolute change in a region's share of production due to differential changes in supply factors was 1.21 percentage points. The comparable averages for changes in per capita consumption and milk support prices were 0.23 and 0.19 percentage points, respectively. 
The 30 percent decline in real milk support prices over 1970 to 1991 increased production shares by at least one-fifth of a percentage point in the Lake States and Southeast, while decreasing production shares by at least one-fifth of a percentage point in the Corn Belt and Pacific states. Largest impact was a 0.55 percentage point decline in the Corn Belt's share of production.

The large population shifts to the south and west over the 1970-1991 analysis period had minimal impact, as did changes in Class I fluid milk differentials and the regional distribution of per capita income. To illustrate the small magnitude of these impacts, the largest absolute change in a region's share of milk production caused by any of these three factors was 0.04 percentage points.

In conclusion, these results underscore the importance of supply variabies in understanding regional shifts in milk production. They do not support complaints that the recent changes in the fluid milk differentials affected the regional distribution of milk production. Furthermore, future declines in the support price is expected to negatively impact milk production in the West and especially the Corn Belt, while positively impacting production in the Lake States and Southeast. 


\section{Endnotes}

1. The representative federal milk marketing order for each region and their minimum Class I price differentials, 3.5 percent butterfat, in dollars per hundredweight (before and after May 1986) are: Northeast: New York-New Jersey (\$2.84 vs. \$3.14); Lake States: Chicago (\$1.27 vs. \$1.40); Corn Belt: Indiana (\$1.53 vs. \$2.00); Northern Plains: Nebraska-Western Iowa (\$1.60 vs. \$1.75); Appalachia: Nashville (\$1.85 vs. \$2.52); Southeast: Upper Florida (\$2.85 vs. \$3.58); Delta States: Greater Louisiana (\$2.47 vs. \$3.28); Southern Plains: Texas (\$2.32 vs. \$3.16); Mountain: Eastern Colorado (\$2.30 vs. \$2.73); and Pacific: OregonWashington (\$1.95 vs. \$1.90) (U.S. Department of Agriculture, Agricultural Marketing Service).

2. No estimate of the elasticity of supply for the other dairy products category was found. Its elasticity is estimated by averaging Sullivan et al.'s elasticities of supply for milk, butter. cheese, and powder.

3. The regions used by Batista and Chavas et al. do not always correspond with the regions used in this study. For a region included in this study but not in Batista or Chavas et al.. the elasticity of supply is estimated by averaging the elasticities for the available regions which overlap the region used in this study. For example, the states included in the Northern Plains in this study fall into two different regions in Batista's study. The average elasticity for these two regions is used as the elasticity for the Northern Plains. 


\section{References}

Batista, J.C. Regional Opportunity Cost of Producing Milk and the Agricultural Production Effects of Alternative Spatial Pricing Policies in Dairying. Ph.D. dissertation, Cornell University. 1985.

Baker, A.D. An Investigation of the Dairy Subsector Impacts of a Free Trade Agreement Between Canada and United States. Ph.D. dissertation, The Pennsylvania State University. 1991.

Blayney, D. and L.Southard. "Dairy Policy to Build on Market Orientation." Agricultural Outlook. U.S. Department of Agriculture. AO-220. July 1995, pages 13-15.

Brooke, A., D. Kendrick, and A. Meeraus. GAMS, A Users' Guide, Release 2.25. The Scientific Press. 1992.

Chavas, J.P., A.F. Kraus, and E.V. Jesse. "A Regional Analysis of Milk Supply Response in the United States." North Central Journal of Agricultural Economics. 12(1990):149-164.

Fallert, R.F., D.P. Blayney, and J.J. Miller. Dairy, Background for 1990 Farm Legislation. U.S. Department of Agriculture, Economic Research Service, Commodity Economics Division. Staff Report AGES 9020. 1990.

George, G. E. St. Spatial Model for Evaluation of Alternative Pricing and Pooling Procedures for the U.S. Dairy Industry. Ph.D. dissertation, The Pennsylvania State University. 1978. Gould, B.W., T.L. Cox, and F. Perali. "The Demand for Fluid Milk Products in the U.S.: A Demand System Approach." Western Journal of Agricultural Economics. 15(1990):1-12. 
Hallberg, M.C., D.E. Hahn, R.W. Stammer. G.J. Elterich, and C.L. Fife. Impact of Alternative Federal Milk Marketing Order Pricing Policies on the United States Dairy Industry. The Pennsylvania State University. Bulletin 818. May 1978.

Heien, D.M. and C.R. Wessells. "The Demand for Dairy Products: Structure, Prediction, and Decomposition." American Journal of Agricultural Economics. 70(1988):219-228.

Huang, K.S. U.S. Demand for Food: A Complete System of Price and Income Effects. U.S. Department of Agriculture, Economic Research Service, National Economic Division. Technical Bulletin 1714. December 1985.

McDowell, F.H. Domestic Dairy Marketing Policy: An Interregional Trade Approach. Ph.D. dissertation, The University of Minnesota. 1982.

Moede, H.H. Out-of-Market Bulk Milk Shipment Charges for Selected Federal Order Markets. U.S. Department of Agriculture, Economic Research Service. Marketing Research Repori No. 959.1972.

Putnam, J.J. and J.E. Allshouse. Food Consumption, Prices, and Expenditures, 1970-93. U.S. Department of Agriculture, Economic Research Service, Food and Consumer Economics Division. Statistical Bulletin 915. December 1994.

Rand McNally. 1992 Commercial Atlas and Marketing Guide. 123rd edition.

Ruane, J.J. and M.C. Hallberg. Spatial Equilibrium Analysis for Fluid and Manufacturing Milk in the United States, 1967. The Pennsylvania State University. Bulletin 783. 1972.

Samuelson, P.A. "Spatial Price Equilibrium and Linear Programming." The American Economic Review. 42(1952):283-303. 
Schiek, W.A. "Regional Impacts of Federal Milk Marketing Order Policy Alternatıves." Agricultural and Resource Economics Review. 23(1994): 207-217.

Sullivan. J., J. Wainio and V. Roningen. A Database for Trade Liberalization Studies. U.S. Department of Agriculture, Economic Research Service, Agriculture and Trade Analysis Division. ERS Staff Report AGES 89-12. March 1989.

Takayama, T. and G.G. Judge. "Spatial Equllibrium and Quadratic Programming." Journal of Farm Economics. 46(1964):67-93.

U.S. Department of Agriculture, Agricultural Marketing Service. Federal Milk Order Market Statistics. Several issues, 1972-1982.

U.S. Department of Agriculture, Economic Research Service. Dairy Situation and Outlook Report. Several issues, 1961-1992.

U.S. Department of Agriculture, National Agricultural Statistics Service. Agricultural Prices. Several issues, 1960-1990.

U.S. Department of Agriculture, National Agricultural Statistics Service. Milk Production. Several issues, 1960-1992.

U.S. Department of Agriculture, National Agricultural Statistics Service. Milk Production, Disposition and Income. Several issues, 1970-1992.

U.S. Department of Commerce. Statistical Abstract of the United States, the National Data Book. Several issues, 1980-1992.

Weersink, A. and L.W. Tauer. "Regional and Temporal Impacts of Technical Change in the U.S. Dairy Sector." American Journal of Agricultural Economics. 72(1990): 923-934. 
Weersink, A. and W. Howard. "Regional Adjustment Response in the U.S. Dairy Sector to Changes in Milk Support Price." Western Journal of Agricultural Economics. 15(1990): $13-21$. 
Table 1. Comparison of actual ani) Model-Derived Regional Milk Production Shares, U.S., 1970, 1980 , ani 1991.

\begin{tabular}{|c|c|c|c|c|c|c|c|c|c|}
\hline \multirow[b]{2}{*}{ Region } & \multicolumn{3}{|c|}{1970} & \multicolumn{3}{|c|}{1980} & \multicolumn{3}{|c|}{1991} \\
\hline & Actual & Model & Ratio $^{\mathrm{a}}$ & Actual & Model & Ratio $^{d}$ & Actual & Model & Ratio $^{a}$ \\
\hline Northeast & 20.7 & 20.2 & 97 & 20.4 & 20.1 & 99 & 18.6 & 18.4 & 99 \\
\hline Lake States & 27.9 & 28.2 & 101 & 28.7 & 28.2 & 98 & 26.3 & 25.9 & 99 \\
\hline Corn Belt & 14.8 & 14.7 & 99 & 12.4 & 12.5 & 101 & 11.3 & 12.0 & 106 \\
\hline N. Plains & 5.1 & 5.1 & 100 & 4.1 & 4.1 & 100 & 3.5 & 3.5 & 100 \\
\hline Appalachia & 7.0 & 7.0 & 100 & 6.6 & 6.6 & 100 & 5.5 & 5.5 & 99 \\
\hline Southeast & 3.6 & 3.5 & 97 & 3.5 & 3.4 & 97 & 3.3 & 3.2 & 97 \\
\hline Delta States & 2.4 & 2.4 & 100 & 2.0 & 2.0 & 100 & 1.7 & 1.6 & 95 \\
\hline S. Plains & 3.7 & 3.6 & 98 & 3.7 & 3.6 & 97 & 4.5 & 4.3 & 96 \\
\hline Mountain & 4.0 & 4.2 & 104 & 4.8 & 4.9 & 102 & 6.7 & 6.4 & 96 \\
\hline Pacific & 10.8 & 11.2 & 104 & 13.6 & 14.5 & 107 & 18.6 & 19.2 & 103 \\
\hline Total & 100.0 & 100.0 &.-- & 100.0 & 100.0 & -- & 100.0 & 100.0 & -- \\
\hline
\end{tabular}

Note: The States included in each region are Northeast: Maine, New Hampshire, Vermont, Massachusetts, Rhode Island, Connecticut, New York, New Jersey, Pennsylvania, Delaware, Maryland; Lake States: Michigan, Wisconsin, Minnesota; Corn Belt: Ohio, Indiana, Illinois, lowa, Missouri; Northern Plains: North Dakota, South Dakota, Nebraska, Kansas; Appalachia: Virginia, West Virginia, North Carolina, Kentucky, Tennessee; Southeast: South Carolina, Georgia, Florida, Alabama; Delta States: Mississippi, Arkansas, Louisiana; Southern Plains: Oklahoma, Texas; Mountain: Montana, Idaho, Wyoming, Colorado, New Mexico, Arizona, Utah, Nevada; Pacific: Washington, Oregon, California, Alaska, Hawaii.

${ }^{a}$ Share derived from the model divided by actual share.

SOURCE: Original Calculations 
Table 2. Estimates of the Impact of Supply, Demand, and Policy Variables on the Regional Distribution of Milk Production, U.S., 1970-1991

\begin{tabular}{|c|c|c|c|c|c|c|}
\hline \multirow[b]{2}{*}{ Region } & \multirow{2}{*}{$\begin{array}{c}\text { Supply } \\
\text { Variables }\end{array}$} & \multicolumn{3}{|c|}{--.--- Demand Variables --.---- } & \multirow{2}{*}{$\begin{array}{c}\text { Milk } \\
\text { Price } \\
\text { Support }\end{array}$} & \multirow{2}{*}{$\begin{array}{c}\text { Milk } \\
\text { Marketing } \\
\text { Orders }\end{array}$} \\
\hline & & Population & $\begin{array}{l}\text { Per Capita } \\
\text { Income }\end{array}$ & $\begin{array}{c}\text { Per Capita } \\
\text { Consumption }\end{array}$ & & \\
\hline & \multicolumn{6}{|c|}{ Percentage Points - } \\
\hline Northeast & -0.79 & -0.008 & 0.0005 & 0.317 & 0.07 & -0.016 \\
\hline Lake States & -0.42 & -0.013 & 0.0012 & 0.404 & 0.30 & -0.031 \\
\hline Corn Belt & -1.72 & -0.001 & -0.0018 & 0.378 & -0.55 & 0.024 \\
\hline N. Plains & -1.35 & -0.002 & 0.0001 & 0.002 & 0.05 & -0.004 \\
\hline Appalachia & -0.99 & -0.017 & 0.0010 & -0.008 & 0.13 & 0.029 \\
\hline Southeast & -0.12 & 0.037 & 0.0002 & 0.028 & 0.21 & -0.008 \\
\hline Delta States & -0.66 & 0.014 & 0.0001 & -0.005 & 0.08 & -0.003 \\
\hline S. Plains & 0.88 & -0.002 & 0.0004 & -0.075 & 0.12 & -0.007 \\
\hline Mountain & 1.21 & -0.002 & -0.0005 & -0.290 & -0.16 & 0.007 \\
\hline Pacific & 3.98 & -0.006 & -0.0009 & -0.750 & -0.26 & 0.008 \\
\hline
\end{tabular}

Note: See Table 1 for a listing of the states in each region.

SOURCE: Original calculations 
